\title{
Making Intelligent Online Dispute Resolution Tools available to Self-Represented Litigants in the Public Justice System*
}

\author{
Towards and Ethical use of the Al technology in the administration of Justice
}

\author{
Fernando Esteban de la Rosa ${ }^{\dagger}$ \\ University of Granada \\ Granada, Spain \\ festeban@ugr.es
}

\author{
John Zeleznikow ${ }^{\dagger}$ \\ La Trobe University Law School \\ Melbourne, Australia \\ J.Zeleznikow@latrobe.edu.au
}

\begin{abstract}
Over the last decade online dispute resolution (ODR) has moved from merely e-commerce litigation to widespread use in court systems. Two phenomena have led to this situation: the rise of SelfRepresented Litigants and Courts moving beyond their traditional focus, allowing parties, for instance, to file a claim, formulate their arguments, obtain legal information or even a receive a forecast about the resolution of the case. AI tools have mainly been used to enable legal professionals (lawyers, mediators) to better perform their tasks. Today some jurisdictions have begun to provide justice users with truly useful intelligent- user centric ODR systems incorporating assessment and diagnosis AI tools. These tools may provide information about a possible outcome. This paper analyses the use being made by some jurisdictions of combined Online Dispute Resolution and Artificial Intelligence tools and aims to promote the debate on the ethical governance of making these tools available to unrepresented litigants. The evaluation follows a European perspective on the ethical governance of the use of AI in the Justice System.
\end{abstract}

\section{KEYWORDS}

Justice Systems, Intelligent-user centric Online Dispute Resolution Systems, Self-Represented Litigants, Ethics

\section{ACM Reference Format:}

Fernando Esteban de la Rosa and John Zeleznikow. 2021. Making Intelligent Online Dispute Resolution Tools available to Self-Represented Litigants in the Public Justice System: Towards and Ethical use of the AI technology in the administration of Justice. In Eighteenth International Conference for Artificial Intelligence and Law (ICAIL'21), June 21-25, 2021, São Paulo, Brazil. ACM, New York, NY, USA, 5 pages. https://doi.org/10.1145/3462757.3466077

${ }^{*}$ Lodder and Zeleznikow [8] indicate, whilst there is no generally accepted definition of ODR, we can think of it as using the Internet to perform Alternative Dispute Resolution (ADR).

${ }^{\dagger}$ Both authors contributed equally to this research.

Permission to make digital or hard copies of all or part of this work for personal or classroom use is granted without fee provided that copies are not made or distributed for profit or commercial advantage and that copies bear this notice and the full citation on the first page. Copyrights for components of this work owned by others than ACM must be honored. Abstracting with credit is permitted. To copy otherwise, or republish, to post on servers or to redistribute to lists, requires prior specific permission and/or a fee. Request permissions from permissions@acm.org.

ICAIL'21, June 21-25, 2021, São Paulo, Brazil

(C) 2021 Association for Computing Machinery.

ACM ISBN 978-1-4503-8526-8/21/06 . \$ \$15.00

https://doi.org/10.1145/3462757.3466077

\section{INTRODUCTION: THE NEW COMBINED USE OF ONLINE DISPUTE RESOLUTION AND ARTIFICIAL INTELLIGENCE TOOLS IN THE PUBLIC JUSTICE SYSTEM}

Advances in Computing and Information and Communication Technology have opened new possibilities for implementing traditional models of justice systems. The development of the COVID19 pandemic has further enhanced the rise of Online Dispute Resolution (ODR) and led to the incorporation of a wide range of technological tools into dispute resolution. Developments in Artificial Intelligence (AI) hold promises for improving efficiency and quality in the provision of access to justice, leading to improved transparency and standardisation of case-law.

Tania Sourdin [12] has suggested that there are three primary ways in which technology has already restructured the justice system. First, and at the most rudimentary level, are "supportive" technologies - these technologies aim to inform, support and advise individuals involved in the justice system and include, for example, online legal applications (apps). At the second level are "replacement" technologies - these technologies replace the roles and activities traditionally conducted by humans and include, inter alia, e-filing processes and online mediation services. Finally, and at the most advanced level, are "disruptive" technologies - these technologies fundamentally alter the way in which legal professionals work and include, for example, AI judges or other algorithm-based decision-making programs that may reshape the judicial role.

Whilst there are numerous e-courts (for instance in the United Kingdom, USA and Australia), not many jurisdictions have taken the step forward of proposing a combined use of ODR tools designed to provide information in such a way that the parties may obtain a diagnosis or a prediction of the outcome so that disputants can be better prepared to deal with a direct negotiations conducted online. Manifestations of this combination of tools are found today in the Dutch Platform Rechtwijzer, the new Internet Courts in China and the Civil Resolution Tribunal (CRT) in British Columbia (Canada). There are also projects with the same aim in Singapore and in Estonia, in the latter case this includes the creation of a "robot judge".

This paper analyses the combined use of ODR and AI tools in courts, with a special focus on cases where AI tools aim to support Self Represented Litigants (SRL)s in reaching settlements. This combination of tools makes use of the notion of Bargaining in the Shadow of the Law developed by Mnookin and Kornhauser [9]. The 
paper describes the underlying reasons that have triggered the rise of SRLs and includes proposals to ensure their fair treatment.

\section{EXAMPLES INCORPORATING ARTIFICIAL INTELLIGENCE INTO ONLINE DISPUTE RESOLUTION SYSTEMS}

\subsection{The Dutch platform Rechtwijzer}

Rechtwijzer ${ }^{1}$ (Roadmap to Justice) was designed for couples, with children who are separating. The aim of Rechtwijzer was 'to empower citizens to solve their problems by themselves or together with his or her partner. If necessary, it refers people to the assistance of experts.' Couples pay $€ 100$ for access to Rechtwijzer, which starts by asking each partner for information such as their age, income, education, whether they want the children to live with only one parent or part time with each, then guides them through questions about their preferences.

The platform had a diagnosis phase; an intake phase for the initiating party; and then invited the other to join and undertake the same intake process. Once intake is completed, the parties start working on agreements. The dispute resolution model is that of integrative (principled) negotiation[5]. The parties are informed of rules such as those for dividing property, child support and standard arrangements for visiting rights so that they could agree on the basis of informed consent. Agreed agreements are reviewed by a neutral lawyer. If the proposed solutions are not accepted, then couples can employ the system to request a mediator for an additional $€ 360$, or a binding decision by an adjudicator. Rechtwijzer is voluntary and non-binding up until the point where the parties seek adjudication. Rechtwijzer had aimed to be self-financing through user contributions. This has not occurred.

\subsection{The British Columbia Civil Resolution Tribunal}

The British Columbia Civil Resolution Tribunal [11] is the most significant current widely available ODR system that comes closest to providing a full suite of dispute resolution services. It commences by diagnosing the dispute, by providing a decision tree, and provides legal information and tools such as customized letter templates.

If this action does not resolve the dispute, one can then apply to the Civil Resolution Tribunal for dispute resolution. The system directs the user to the appropriate application forms. Once the application is accepted, the user enters a secure and confidential negotiation platform, where the disputants can attempt to resolve their dispute. If the parties cannot resolve the dispute, a facilitator will assist. Agreements can be turned into enforceable orders. If negotiation or facilitation does not lead to a resolution, an independent member will make a determination about the dispute.

Currently, the Civil Resolution Tribunal deals with Motor vehicle injury disputes, Small claims disputes, Strata property disputes, Societies and cooperative associations disputes and Shared accommodation and some housing disputes. For some of these domains potential litigants can only use the Civil Resolution Tribunal.

To assist digitally disadvantaged litigants, technical support is provided in accessing the Internet. One of the major reasons that

\footnotetext{
${ }^{1}$ https://rechtwijzer.nl/ last viewed 5 February 2021
}

the Civil Resolution Tribunal has been so successful, is that British Columbia residents are mandated to use the system when dealing with issues listed above. Whilst such an approach may be seen novel and discriminatory, it does ensure that the system is used, with relative ease, quickly and at minimal cost. In most cases parties are to represent themselves, even if representation and legal assistance is allowed.

\subsection{The Internet Courts in China}

Between 2017 and 2018 China created three new Courts: the Hangzhou Internet Court, the Beijing Internet Court and the Guangzhou Internet Court. These courts only have material jurisdiction over internet-related cases. The online platform makes an intelligent litigation risk assessment system available to the user and can provide a report synthesising the litigants' case and the corresponding risk based on the analysis of court data and similar cases. Litigation risk assessment aims to help the party without legal knowledge to identify and exclude common litigation risks, thereby reducing unnecessary losses. Meanwhile, the assessment can make the party aware that litigation is risky and costly and guide the parties to choose ADR or diversified dispute resolution. The system can automatically generate a complaint letter by simply selecting the suitable response options. [4]

\subsection{Projects in Estonia and Singapore}

In July 2019 the Estonian Ministry of Justice launched a project developing AI software to hear and resolve small economic disputes by eliminating human intervention [10]. The "robot judge" is configured to decide disputes of up to 7,000 euros. According to the project, the disputing parties would have to upload their documents and relevant information to a judicial platform. The AI machine renders a decision that can be appealed to a human judge. The project limits its scope to contractual disputes.

Singapore has been committed to digital justice since 2000. In recent years it has been developing a more ambitious online system, initially only for injuries arising from motor vehicle accidents. An outcome simulator will provide guidance to potential claimants, prior to the commencement of proceedings, helping them to decide on offers from insurance companies. The aim is for parties to first use the technology to reach amicable settlements without professional legal advisors [14].

\section{A FRAMEWORK FOR BUILDING ONLINE DISPUTE RESOLUTION TOOLS FOR SELF-REPRESENTED LITIGANTS}

An increasing phenomenon in Common Law countries is the growing number of pro se (or self-represented) litigants. Landsman [7] argues that pro se cases pose inherent problems: they can cause delays, increase administrative costs, undermine the judges' ability to maintain impartiality and can leave the often-unsuccessful litigant feeling as though she has been treated unfairly.

Research conducted in the Family Court of Australia shows that there are a range of reasons why people represent themselves, such as funding cuts and changes in eligibility to legal aid [3]. Other contributing factors include changes in technology, cultural shifts towards self-help and self-representation, and changes in 
legislation. The experiences of self-representation in Australian law has generally accepted that SRLs are at a disadvantage in legal proceedings and their experience of the legal system may indeed be negative. The lack of knowledge or skills of SRLs means that some are not able to access fair and equal justice in a system often geared towards legal representation.

In England litigants can go to court without legal aid, in practice the technical and formal nature of proceedings, with the exception of the small claims procedure (for claims up to $£ 10,000$ ), makes legal aid necessary. Its lack has led to public dissatisfaction but also frustration among judges, faced with the need to inform lay litigants about the technicalities of the process without being able to cross the line between information and legal aid. This situation led to a considerable increase in the time and cost spent on each judicial decision, even doubling it $^{2}$. While some SRLs can present their case competently, most research suggests that SRLs struggle with substantive law and procedure [6].

Recent experiences, such as the online court established in Utah, are demonstrating that ODR has the potential to transform the way the American legal system deals with pro se litigants and access to justice issues at large. Although it may seem counterintuitive to bridge the justice gap by precluding people from appearing in court, requiring certain types of claims to begin online will actually provide quicker and more accessible legal solutions. As long as the programming and administration of ODR technology are conducted with attention to legal and ethical concerns, pro se litigants will benefit from having their claims resolved online [2]. For this aim access to justice is helped by the use of intelligent-user centric ODR systems incorporating assessment and diagnosis AI tools [15].

Stranieri et al. [13] approach for providing advice about the distribution of marital property following divorce in Australia was to use machine learning to provide advice about BATNAs (a BATNA is used to inform disputants of the likely outcome if the dispute were to be decided by decision-maker e.g. judge, arbitrator or ombudsman). Despite using Machine Learning, it involved the development of 94 Toulmin argument structures [16] to model the domain as it existed in 1995. Twenty-five years later, the theoretical principles behind machine learning software have not changed. But computer hardware is now much cheaper and data can be much more easily stored. This has led to the development of 'quicker; systems', which the community has seen as 'more intelligent'3.

Whilst the Split-Up system provides advice about BATNAs, the Family Winner System [1] provided advice to disputing parents on how they could best negotiate trade-offs. The disputing parties were asked to indicate how much they valued each item in dispute. Using logrolling, parties obtained what they most desired.

Zeleznikow [20] discusses how it is possible to build ODR systems that support self-represented litigants and what skills do selfrepresented litigants require to use such systems. Zeleznikow [21] considers how we can construct such systems with user centric computing. So, what are the various types of ODR systems and how can self-represented litigants use them? Having regard to the

\footnotetext{
${ }^{2}$ JUSTICE, "Delivering Justice in an Age of Austerity" (April 2015). Available in https //justice.org.uk/justice-age-austerity-2/ last viewed 19 April 2021

${ }^{3}$ See for example amica.gov.au which uses machine learning to advise upon property distribution amongst separating couples in Australia.
}

vulnerable position of the unrepresented litigant a truly helpful ODR system should provide the following facilities:

(1) Case management: the system should allow users to enter information, ask them for appropriate data and provide for templates to initiate the dispute. Self-represented litigants should be able to initiate the dispute, enter their pertinent data and also track what is happening during the dispute as well as being aware of what documents are required at specific times;

(2) Triaging: the system should provide information on how important it is to act in a timely manner and where to send the dispute. This may be particularly important in cases of domestic abuse or where there is a potential for children to be kidnapped. Triaging systems are vital for expediting action in high risk cases;

(3) Advisory tools: the system should provide tools for reality testing: these could include, books, articles, reports of cases, copies of legislation and videos; there would also be calculators (such as to advise upon child support) and BATNA advisory; systems (to inform disputants of the likely outcome if the dispute were to be decided by decision-maker (e.g. judge, arbitrator or ombudsman). Advisory tools, as suggested by Zeleznikow [19] are a vital cog in supporting self-represented litigants. An important associated question is how can we design advisory tools that self-represented litigants can gainfully use? Are the legal concepts behind these tools too difficult for amateurs to understand? How do we construct suitable user interfaces?

(4) Communication tools - for negotiation, mediation, conciliation or facilitation. This could involve shuttle mediation if required. For many ODR providers, the provision of communication tools is their main goal;

(5) Decision Support Tools - if the disputants cannot resolve their conflict, software using game theory or AI can be used to facilitate trade-offs. Professionals (such as lawyers) can provide useful advice re trade-offs. In their absence, suitable decision support tools are vital;

(6) Drafting software: if and once a negotiation is reached, software can be used to draft suitable agreements. Drafting plans (such as parenting plans) once there is an in-principle agreement for a resolution of a dispute, is a non-trivial task.

No single dispute is likely to require all six processes. However, the development of such a hybrid ODR system would be very significant. A total system would require us to construct the appropriate systems 1 to 6 , and the ultimate solution is to make sure that all the systems are capable of communicating with each other.

\section{ETHICAL ISSUES RELATING TO THE PROVISION OF ARTIFICIAL INTELLIGENCE-BASED TOOLS TO SELF-REPRESENTED LITIGANTS BY THE PUBLIC JUSTICE SYSTEM: A EUROPEAN PERSPECTIVE}

Neither the recent official documents of the European Union determining how AI should be used in the field of the administration of 
justice $^{4}$ nor the European Ethical Charter (EEC) on the use of AI in judicial Systems and their environment adopted in 2018 by the European Commission for the Efficiency of Justice of the Council of Europe deal directly with the admission of AI tools aimed at enabling the parties to assess their legal position. Because SRLs generally lack legal skills and in view of the objective to encourage negotiation we submit that this use of technology for these purposes should be considered high-risk.

The EEC points out the inherent risks in these technologies may even transcend the act of judging and affect essential functioning elements of the rule of law and judicial systems. These include principles such as the primacy of law. These tools could create a new form of normativity, which could supplement the law by regulating the sovereign discretion of the judge, and potentially leading, in the long term, to a standardisation of judicial decision based no longer on case-by-case reasoning by the courts, but on a pure statistical calculation linked to the average compensation previously awarded by other courts. That is why the report submits a need to consider whether these solutions are compatible with the individual rights enshrined in the European Convention on Human Rights (ECHR). These would include the rights to a fair trial (particularly the right to a natural judge established by law, the right to an independent and impartial tribunal and equality of arms in judicial proceedings) and, where insufficient care has been taken to protect data communicated in open data, the right to respect for private and family life. Thus the EEC considers that applications of predictive justice should be assigned to the field of research and further development in order to ensure that they fully tie in with actual needs before contemplating use on a significant scale in the public sphere.

The European Commission (EC) recognises that the use of AI applications can bring many benefits, such as making use of information in new and highly efficient ways, and improve access to justice, including by reducing the duration of judicial proceedings. At the same time it is aware that the opacity or biases embedded in certain AI applications can also lead to risks and challenges for the respect of and effective enforcement of fundamental rights, including in particular the right to an effective remedy and a fair trial. The EC recognises as a possible high-risk a use case using the technology as part of decision-making processes with significant effects on the rights of people. However, it also considers that the proposed requirements in the White Paper on increased transparency, human oversight, accuracy and robustness of these systems aim to facilitate their beneficial use, while ensuring that fundamental rights including non-discrimination based on sex, racial or ethnic

\footnotetext{
${ }^{4}$ Among the last official documents are the Proposal for a Regulation Laying down Harmonised Rules on Artificial Intelligence (Artificial Intelligence Act) and Amending Certain Union Legislative Act of 21.4.2021 COM (2021) 206 final; the Communication from the Commission to the European Parliament, the Council, the European Economic and Social Committee and the Committee of the regions called "Digitalisation of justice in the European Union. A toolbox of opportunities", COM (2020) 710 final, of 2.12.2020 the European Parliament Resolution of 20 October 2020 with recommendations to the Commission on a framework of ethical aspects of artificial intelligence, robotics and related technologies (2020/2012 (INL); White Paper on Artificial Intelligence - A European approach to excellence and trust, $\operatorname{COM}(2020) 65$ final of Brussels, 19.2.2020 the European e-Justice Strategy 2019-2023 of 13 March 2019 (2019/C 96/04) Council 2019-2023; the Digital Revolution in view of Citizens' Needs and Rights. Opinion of the European Economic and Social Committee of 20.02.2019.
}

origin, religion or belief, disability, age or sexual orientation) are respected and rule of law and due process principles upheld.

In order to understand the European position it is also relevant to know the criterion followed by the new proposal for a Regulation of April 2021. AI systems intended for the administration of justice are not listed among the prohibited practices (art. 5) but among the highrisk AI systems (point 40 of the preamble). The new proposal for a Regulation separates two kinds of judicial activities: it is considered as high-risk the systems intended to assist judicial authorities in researching and interpreting facts and the law and in applying the law to a concrete set of facts. Such qualification is not extended to AI systems intended for purely ancillary administrative activities that do not affect the actual administration of justice in individual cases. The proposed Regulation does not establish the definitive answer as any use of AI must continue to occur solely in accordance with the applicable requirements resulting from the European Charter of Fundamental Rights, the rest of European Law and the national law.

We submit that in view of the beneficial impact it may have on the functioning of the judicial system, it is necessary to identify the real possibilities, technical limits and safeguards to be met by the machines offered by the public justice system to SRLs.

For specific areas of administrative law it is possible to develop legal rules as code providing useful information and support for SRLs. The use of code as rules in combination with User Centric ODR Tools using decision trees, may have success promoting access to justice for SRLs. The CRT in the British Columbia is an example of success. The design of AI rule-based systems does not exhibit the difficulties arising from the lack of transparency and the creation of biases that may arise employing ML induction algorithms. Deductive AI tools (the so called Experts Systems) allow transparency and the monitoring of the machine output is facilitated to be able to rectify what is necessary in case any errors in the programming are discovered. Programming is, however, a delicate process and if not done well can lead to unfair treatment when the algorithm doesn't match reality. This can occur when a one-sizefits-all rule is implemented in a complex environment. A recent example is Australia's Centrelink "robodebt" debacle 5 . In that case, welfare payments made on the basis of self-reported fortnightly income were cross-referenced against an estimated fortnightly income, taken as a simple average of annual earnings reported to the Australian Tax Office, and used to auto-generate debt notices without any further human scrutiny or explanation. This assumption is at odds with how Australia's highly casualised workforce is actually paid. For example, a graphic designer who was unable to find work for nine months of the financial year but earned $A \$ 12,000$ in the three months before June would have had an automated debt raised against her. This is despite no fraud having occurred, and this scenario constituting exactly the kind of hardship Centrelink is designed to address.

Rules as codes requires alterations to be introduced in case of legislative changes. Although it will not be possible to attain the quality of advice offered by a legal expert, we submit that the information provided to SRLs through machines makes a contribution to

\footnotetext{
${ }^{5}$ See https://tinyurl.com/y3dqe6mg last viewed 19 April 2019
} 
improving access to justice for those who cannot afford legal assistance. Regarding the quality of advice provided by these machines, it seems reasonable that the proposals of the European Commission about requirements concerning possible testing of applications and the need to provide relevant documentation on their purposes and functionalities. It seems also reasonable to require maintaining the possibility to correct errors and providing information to the user that the answer given by the machine may not necessarily match the answer that would be given by a judge hearing the case.

Two of the disadvantages of the use of Machine Learning systems are that they are not transparent, and the data and the software on which they are based may be manipulated. There is also a concern that the use of Machine Learning in the legal system will worsen biases against minorities or deepen the divide between those who can afford quality legal assistance and those who cannot [17]. Algorithms will continue to perform existing biases against vulnerable groups because the algorithms are largely copying and amplifying the decision-making trends embedded in the legal system. There is already a class divide in legal access - those who can afford high quality legal professionals will always have an advantage. The development of intelligent support systems can partially redress this power imbalance by providing users with important legal information that was previously unavailable to them. Difficulties may stem from biases. One example is COMPAS, a decision support system designed to help parole boards in the United States [18] decide which prisoners to release early, by providing a probability score of their likelihood of reoffending. Rather than rely on a simple decision rule, the algorithm used a range of inputs, including demographic and survey information, to derive a score. The algorithm did not use race as an explicit variable, but it did embed systemic racism by using variables that were shaped by police and judicial biases.

What can be done is to ensure the traceability and cleanliness of the data with which the machine operates, and to introduce elements of weighting. But as Richard Susskind considers, an ethical programming is not feasible. It is not at all clear, either technically or philosophically, what is meant when it is proposed that ethics should be embedded in Machine Learning. Nor it is clear what is meant when it is demanded that software engineers program Machine Learning systems to provide intelligent explanations. To think so is to misunderstand the difference between the inductive processes inherent in Machine Learning and the kind of argument we expect when we ask for an explanation [14].

A different issue is the use of AI tools by judges to decide a case. We share the European Commission's view that it is important that judgments are delivered by judges who fully understand the AI applications and all information taken into account therein that they might use in their work (AI not to replace but as Augmented Intelligence), on the understanding that the use of AI applications must not prevent any public body from giving explanations for its decisions. As for the machine being able to decide the case on its own, as the Estonian project poses, this should not be completely ruled out. However, we are not at that stage yet! In the current state of the art, machines can neither motivate nor explain the decisions and predictions they make [14]. Legal arguments require persuasion that does not depend on predictable variables.

\section{CONCLUSION}

One of the latest trends in the incorporation of technology in the administration of justice is the provision by public justice systems to support SRLs by the use of a combination of AI and ODR tools. These allow SRLS to have a diagnosis of the case, which influences the parties either to determine a dismissal of the action or how to negotiate. This combination of tools shows great potential in reducing the level and duration of litigation. The paper submits that this use of the technology must be considered as high risk as it may function as a replacement of judicial activities. However, it is still possible to obtain positive results from this technology by inserting some safeguards, as is beginning to emerge from the European legal sphere. The debate is now about what safeguards are necessary to ensure that the use of high-risk artificial intelligence tools in the field of justice is fully compatible with the rule of law. The implementation and use of this technology should be preceded by the detection and diagnosis of the functioning of justice in specific sectors, so that the efforts are made in the areas with most pressing needs.

\section{REFERENCES}

[1] Emilia Bellucci and John Zeleznikow. 2006. Developing Negotiation Decision Support Systems that support mediators: a case study of the Family_Winner system. Fournal of Artificial Intelligence and Law 13, 2 (2006), 233-271.

[2] Julianne Dardanes. 2021. When Accessing Justice Requires Absence from the Courthouse: Utah's Online Dispute Resolution Program and the Impact it Will Have on Pro Se Litigants. Pepperdine Dispute Resolution Law fournal 21, 1 (2021).

[3] John Dewar, Barry W. Smith, and Cate Banks. 2000. Litigants in Person in the Family Court of Australia - Research Report No 20, Family Court of Australia. Vol. Research Report No 20. Family Court of Australia Canberra.

[4] Xuhui Fang. 2018. Recent Development of Internet Courts in China. International fournal on Online Dispute Resolution 5 (2018), 1-2, 49-55.

[5] Roger Fisher and William Ury. 1981. Getting to yes. Penguin Group, New York.

[6] Hazel Genn and Yvette Genn. 1989. The effectiveness of representation at tribunals. Lord Chancellor's Department.

[7] Stephan Landsman. 2009. The growing challenge of pro se litigation. 13 Lewis \& Clark L. Rev. 439 (2009).

[8] Arno Lodder and John Zeleznikow. 2010. Enhanced dispute resolution through the use of information technology. Cambridge University Press.

[9] Robert H. Mnookin and Lewis Kornhauser. 1979. Bargaining in the shadow of the law: The case of divorce. The Yale Law fournal 88, 5 (1979), 950.

[10] Eric Niiler. 2019. Can AI be a Fair Judge in Court? Estonia Thinks So. https: //www.wired.com/story/can-ai-be-fair-judge-court-estonia-thinks-so/

[11] Shannon Salter and Darin Thompson. 2016. Public-Centred Civil Justice Redesign: A Case Study of the British Columbia Civil Resolution Tribunal”. McGill fournal of Dispute Resolution 3 (2016), 113.

[12] Tania Sourdin. 2018. Judge v. Robot: Artificial Intelligence and Judicial DecisionMaking. UNSWL 41 (2018), 1114.

[13] Andrew Stranieri, John Zeleznikow, Mark Gawler, and Bryn Lewis. 1999. A hybrid rule-neural approach for the automation of legal reasoning in the discretionary domain of family law in Australia. Artificial intelligence and Law 7, 2-3 (1999).

[14] Richard E. Susskind. 2019. Online courts and the future of justice. Oxford University Press.

[15] Darin Thompson. 2015. Creating New Pathways to Justice Using Simple Artificial Intelligence and Online Dispute Resolution. International fournal of Online Dispute Resolution 4 (2015).

[16] S. Toulmin. 1958. The Uses of Argument. Cambridge University Press, Cambridge.

[17] Peter K. Yu. 2020. The Algorithmic Divide and Equality in the Age of Artificial Intelligence, 72 FLA. L. REV 331 (2020).

[18] Monika Zalnieriute, Lyria Bennett Moses, and George Williams. 2019. The rule of law and automation of government decision-making. The Modern Law Review 82,3 (2019), 425-455.

[19] J. Zeleznikow. 2002. Using Web-based Legal Decision Support Systems to Improve Access to. Fustice Information and Communications Technology Law 11, 1 (2002).

[20] John Zeleznikow. 2020. The challenges of using Online Dispute Resolution to support Self Represented Litigants. Journal of Internet Law 3 23, 7 (2020).

[21] John Zeleznikow. 2021. Using Artificial Intelligence to provide Intelligent Dispute Resolution Support. Group Decision and Negotiation (2021). https://doi.org/10. 1007/s10726-021-09734-1 